\title{
In Situ Studies on Temperature-Dependent Photocatalytic Reactions of Methanol on $\mathrm{TiO}_{2}(110)$
}

Ruidan Zhang, ${ }^{\dagger, \ddagger}$ Haochen Wang, ${ }^{\ddagger} \perp$ Cic Xingxing Peng, ${ }^{\dagger, \ddagger}$ Ran-ran Feng, ${ }^{\dagger, \S}$ An-an Liu, ${ }^{\dagger}$ Qing Guo, ${ }^{\ddagger}$ Chuanyao Zhou, ${ }^{\ddagger}$ Zhibo Ma, ${ }^{*}+$ Xueming Yang, ${ }^{+}, \|$Ying Jiang, ${ }^{\dagger}$ and Zefeng Ren ${ }^{*},+,+(0)$

${ }^{\dagger}$ International Center for Quantum Materials (ICQM) and School of Physics, Peking University, 5 Yiheyuan Road, Beijing 100871, P. R. China

${ }^{\ddagger}$ State Key Laboratory of Molecular Reaction Dynamics, Dalian Institute of Chemical Physics, Chinese Academy of Sciences, 457 Zhongshan Road, Dalian 116023, Liaoning, P. R. China

${ }^{\S}$ Key Laboratory of Microgravity (National Microgravity Laboratory), Beijing Key Laboratory of Engineered Construction and Mechanobiology, Institute of Mechanics, Chinese Academy of Sciences, Beijing 100190, China

"Department of Chemistry, Southern University of Science and Technology, 1088 Xueyuan Road, Shenzhen 518055, Guangdong, P. R. China

ABSTRACT: We studied the photocatalytic reaction of methanol on the $\mathrm{TiO}_{2}(110)$ surface in situ by surface sum frequency generation vibrational spectroscopy. The in situ vibrational spectra of the photo-oxidation product, formaldehyde and methyl formate, on $\mathrm{TiO}_{2}(110)$ was unambiguously assigned and identified. The temperature-dependent photocatalytic reaction efficiency was observed and suggested that the thermal diffusion might be important for the photocatalytic reaction. Scanning tunneling microscopy combined with ultraviolet light was used to investigate the photocatalytic reaction efficiency on the hydroxylated $\mathrm{TiO}_{2}(110)$ surface, which shows that the neighboring hydroxyl group on the bridge-bonded oxygen site dramatically inhibits the photooxidation of methanol because of the repulsion between hydroxyl groups. Our results provide direct vibrational spectral evidence of photo-oxidation products of methanol on $\mathrm{TiO}_{2}(110)$, show the importance of thermal processes in surface photocatalytic reactions, and deepen our understanding on photochemistry on this surface.

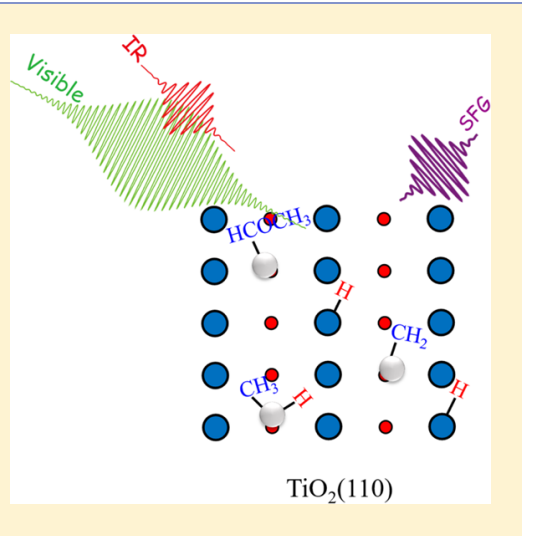

\section{INTRODUCTION}

Titanium dioxide, $\mathrm{TiO}_{2}$, has attracted great interest because of its promising application in photocatalytic splitting of water, photodegradation of environmental pollutants, surface superwetting, and so on. ${ }^{1-7}$ Methanol, as a simplest alcohol, is often used in benchmark studies of the photocatalytic mechanism on $\mathrm{TiO}_{2}$ for explanation of oxide surface properties. ${ }^{8-15}$ In addition, methanol, as a hole scavenger, can dramatically enhance the photocatalytic activity to split water to hydrogen. ${ }^{16-20}$ In the last decade, numerous studies have been carried out on the prototypical model of the photocatalytic reaction of methanol on the rutile $\mathrm{TiO}_{2}(110)$ surface. ${ }^{14,21-26}$ However, the mechanism of photocatalytic processes on $\mathrm{TiO}_{2}$ has not been satisfied to date, especially in the atomic and molecular level.

It is well known that in thermal chemistry, the most active site on $\mathrm{TiO}_{2}(110)$ is the bridge-bonded oxygen $\left(\mathrm{O}_{\mathrm{b}}\right)$ vacancy site. Alcohol molecules adsorb on the $\mathrm{O}_{b}$ vacancy site and spontaneously dissociate to form the alkoxyl and the hydroxyl $\left(\mathrm{OH}_{\mathrm{b}}\right)$ groups. ${ }^{3,5,11}$ The recombination of $\mathrm{OH}_{\mathrm{b}}$ to form water can happen at about $450 \mathrm{~K},{ }^{8}$ which competes with the formation of molecular hydrogen. ${ }^{27}$ The most abundant photocatalytic reactions occur on the five-coordinated $\mathrm{Ti}$ site $\left(\mathrm{Ti}_{5 \mathrm{c}}\right){ }^{6,21,22}$ The mixed adsorption structure of molecular and dissociated methanol on $\mathrm{Ti}_{5 c}$ sites was provided recently by surface sum frequency generation vibrational spectroscopy (SFG-VS), and it was also found that the percentage of the dissociated methanol in the first layer decreases as the coverage increases to more than one layer. ${ }^{28}$ The stepwise photooxidation of methanol to formaldehyde and further to methyl formate on $\mathrm{TiO}_{2}(110)$ was observed. ${ }^{24-26}$

Temperature-programmed desorption (TPD) is the most commonly used method and a powerful tool to study the mechanism of $\mathrm{CH}_{3} \mathrm{OH} / \mathrm{TiO}_{2}(110)$ photocatalytic reaction, especially together with ultraviolet (UV) light sources and intense UV lasers, as reported in the last decade. ${ }^{21-27,29}$ However, TPD probes the species desorbing from the surface, which sometimes could be from the reaction during the heating process of the substrate. X-ray photoelectron spectroscopy has also been used to identify the photocatalytic product of methanol on $\mathrm{TiO}_{2}(110){ }^{25}$ To determine the chemical nature of surfaces and adsorbates, the surface vibrational spectroscopy has gained wide recognition for its ability, ${ }^{30}$ such as reflection-absorption infrared spectroscopy.

Received: March 10, 2019

Revised: March 25, 2019

Published: March 26, 2019 
However, it is difficult to obtain the vibrational spectra on oxides because of the absence of an image dipole and strongly reduced reflectivity. ${ }^{31}$

In this study, we used surface SFG-VS to obtain the vibrational spectra in the $\mathrm{C}-\mathrm{H}$ stretching range of photocatalytic products of methanol on $\mathrm{TiO}_{2}(110)$. The SFG spectra clearly shows the vibrational features from formaldehyde and methyl formate on $\mathrm{TiO}_{2}(110)$. We also compared the photocatalytic reaction efficiencies at substrate temperature of 120 and $180 \mathrm{~K}$. Our results suggested that thermal processes of methanol and photocatalytic reaction products or the repulsion from $\mathrm{OH}_{\mathrm{b}}$ could limit the reaction rate. To elucidate the effect from $\mathrm{OH}_{\mathrm{b}}$, scanning tunneling microscopy (STM) combined with UV light was employed to investigate the photodissociation of methanol on the hydroxylated $\mathrm{TiO}_{2}(110)$ surface.

\section{EXPERIMENTAL DETAILS}

All SFG measurements were conducted in a compact high pressure/ultrahigh vacuum (UHV) chamber, which is described in detail elsewhere. ${ }^{32}$ Commercial rutile $\mathrm{TiO}_{2}(110)$ single crystal (Princeton Scientific) was at $45^{\circ}$ with the crystal orientation [001] relative to the plane of light incidence. Sample preparation was done by cycles of $500 \mathrm{eV} \mathrm{Ar}^{+}$ion sputtering and vacuum annealing at $850 \mathrm{~K}$. Methanol (99.95\% purity) was further purified by several freeze-pump-thaw cycles before the experiment. Almost one layer coverage of methanol was prepared by overdosing methanol at $120 \mathrm{~K}$ and subsequent flashing of the substrate at $216 \mathrm{~K}^{8}$

The optical system of SFG-VS has been described elsewhere. ${ }^{28}$ The regenerative amplifier (Spitfire Ace, Spectra-Physics) generated 35 fs pulses with $5 \mathrm{~mJ}$ per pulse at a 1 $\mathrm{kHz}$ repetition rate at the central wavelength of $800 \mathrm{~nm}$. About $3 \mathrm{~mJ}$ was used to pump an optical parametric amplifier (TOPAS-C, Light Conversion) and a noncollinear difference frequency generator (NDFG1, Light Conversion), which delivered a tunable IR $(2.6-9 \mu \mathrm{m})$ in a silver gallium disulfide $\left(\mathrm{AgGaS}_{2}\right)$ crystal. The central wavelength used in this work was about $3.4 \mu \mathrm{m}$ with an apparent spectral bandwidth of about $300 \mathrm{~cm}^{-1}$ full-width at half-maximum (fwhm). $20 \mathrm{~mW}$ of IR measured before the $\mathrm{CaF}_{2}$ window on the UHV chamber was used in our measurements. About $1 \mathrm{~mJ}$ of $800 \mathrm{~nm}$ pulses was spectrally narrowed as the visible light (VIS) by using a pulse shaper $(1800 \mathrm{l} / \mathrm{mm}$ pulse compression grating, Spectrogon; cylindrical lens with $200 \mathrm{~mm}$ focal length), normally $4.5 \mathrm{~cm}^{-1}$ fwhm and $7.5 \mathrm{~mW}$. The residual $1 \mathrm{~mJ}$ was used to generate second harmonic UV light at $400 \mathrm{~nm}$. UV light $(4 \mathrm{~mW})$ was soft-focused to about $1.5 \mathrm{~mm}$ diameter on $\mathrm{TiO}_{2}(110)$. The IR and VIS pulses were temporally and spatially overlapped on the surface, and the reflected broadband SFG signal was dispersed by a monochromator and then detected by an electron-multiplying charge-coupled device (Princeton Instrument). The incidence angles of SFG, VIS, and IR were $47.9^{\circ}, 45^{\circ}$, and $57^{\circ}$, respectively. Both polarizations of the VIS and IR were controlled by true zeroorder half-wave plates, and the SFG signal polarization was selected and controlled by the combination of an achromatic half-wave plate and a Glan polarizer. The measured SFG spectra were normalized to the SFG signal of ppp (referring to p-polarized SF output, p-polarized visible input, and ppolarized IR input, respectively) polarization combination on the bare $\mathrm{TiO}_{2}(110)$ surface obtained by flashing the sample to $700 \mathrm{~K}$ in UHV.
STM experiments were performed in an UHV chamber equipped with a low-temperature STM (Omicron, MATRIX). The vacuum system was baked out for more than $100 \mathrm{~h}$ to reduce the residual water to get a base pressure better than 3.5 $\times 10^{-11}$ mbar. The $\mathrm{TiO}_{2}(110)$ sample (Princeton, $5 \mathrm{~mm} \times 10$ $\mathrm{mm} \times 2 \mathrm{~mm}$ ) was prepared by multiple cycles of sputtering in $1000 \mathrm{eV} \mathrm{Ar}^{+}$ions for $10 \mathrm{~min}$ and annealing at $\sim 900 \mathrm{~K}$ for 30 min. During annealing, the sample was mounted on a standard Omicron sample Ta plate holder and heated with a pyrolytic boron nitride heater located behind the sample plate. After this procedure, the concentration of oxygen vacancy was about $10 \%$. The sample was cooled down to $80 \mathrm{~K}$ on the stage of the STM scanner which is mounted under a liquid nitrogen dewar. An electrochemically etched tungsten tip was used and all the images were obtained using the constant current mode with a tunneling voltage of $1.25 \mathrm{~V}$ and a tunneling current of $100 \mathrm{pA}$. All the STM images were processed using SPIP software (Image Metrology). As reactants, water and methanol (SigmaAldrich) were purified by several freeze-thaw-freeze cycles to remove existing impurities using liquid nitrogen. The molecules were dosed in situ onto the $\mathrm{TiO}_{2}(110)$ surface through a retractable and calibrated doser with a pinhole, and the distance between the sample and pinhole was about $4 \mathrm{~cm}$. This method can minimize contamination of the UHV system. During dosing and laser irradiation, the tip was retracted about $20 \mu \mathrm{m}$ from the sample to avoid the shadowing effect. The third-harmonic $(355 \mathrm{~nm}$ ) output of a $1064 \mathrm{~nm}$ Q-switched HIPPO laser (Spectra-Physics) was used in our experiments, which had a duration of about $12 \mathrm{~ns}$ and a high repetition of 50 $\mathrm{kHz}$. The $\mathrm{TiO}_{2}(110)$ sample was illuminated by the laser with an incident angle about $27^{\circ}$ through a viewport on the chamber. The beam diameter of laser was $\sim 5 \mathrm{~mm}$ and laser power from 20 to $200 \mathrm{~mW}$ was used. After laser irradiation, the increase of sample's temperature was less than $2 \mathrm{~K}$.

\section{RESULTS AND DISCUSSION}

3.1. Temperature-Dependent Photocatalytic Reactivity of Methanol on $\mathrm{TiO}_{2}(110)$ by SFG Studies. Figure 1 shows the SFG vibrational spectra of methanol with one monolayer coverage on the $\mathrm{TiO}_{2}(110)$ surface before and after different $400 \mathrm{~nm}$ UV irradiation durations. All the SFG spectra were taken at the substrate temperature of $120 \mathrm{~K}$, and the substrate was kept at $120 \mathrm{~K}$ when it was irradiated by UV light. The spectra show complicated features, including symmetric stretching, $\nu_{s}$, Fermi resonance, and antisymmetric stretching from both dissociative adsorbed methanol (methoxy, $\mathrm{CH}_{3} \mathrm{O}-$ $\left.\mathrm{Ti}_{5 \mathrm{c}}\right)$ and molecular adsorbed methanol $\left(\mathrm{CH}_{3} \mathrm{OH}-\mathrm{Ti}_{5 \mathrm{c}}\right)$ at $\mathrm{Ti}_{5 \mathrm{c}}$ sites. Recently, we have successfully assigned these spectra in this $\mathrm{C}-\mathrm{H}$ stretching region by means of SFG polarizationdependent, methanol coverage-dependent, and UV irradiation treatments. ${ }^{33}$ The features at 2806 and $2841 \mathrm{~cm}^{-1}$ are assigned to $\mathrm{CH}_{3}$ symmetric stretching modes from methoxy and molecular-adsorbed methanol at $\mathrm{Ti}_{5 \mathrm{sc}}$, respectively. The Fermi resonances and $\mathrm{CH}_{3}$ antisymmetric stretching of these two species are highly overlapped in the range from 2887 to 3000 $\mathrm{cm}^{-1}$. The ssp (referring to s-polarized SF output, s-polarized visible input, and p-polarized IR input, respectively) SFG spectra in Figure 1a show that the methoxy peak (indicated by the blue dashed line) decreases with the UV irradiation time, whereas the peak for methanol (indicated by red dashed line) seems the same but broader. Even after further $5 \mathrm{~min}$ of UV irradiation, methoxy only decrease a little. It seems the reaction almost stops. The ppp SFG spectra in Figure $1 \mathrm{~b}$ show the 


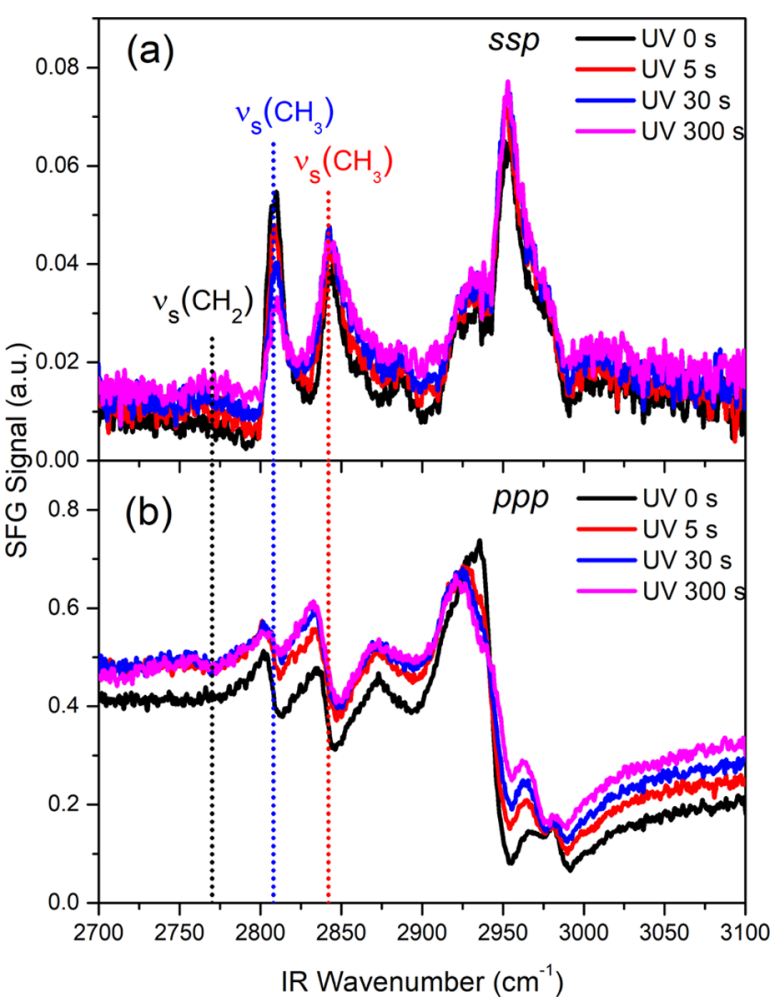

Figure 1. SFG vibrational spectra with ssp (a) and ppp (b) polarization combinations of methanol with one-layer coverage on the $\mathrm{TiO}_{2}(110)$ surface before and after variant UV irradiation times at $400 \mathrm{~nm}$. The substrate was kept at $120 \mathrm{~K}$ when the substrate was irradiated by UV and the SFG spectra were taken. Vertical dashed lines indicate the resonant frequencies of methoxy (blue), methanol (red), and formaldehyde (black) on $\mathrm{Ti}_{5 c}$ sites.

similar trend as the ssp SFG spectra. However, the ppp SFG spectra after UV irradiation show an additional weak feature at about $2770 \mathrm{~cm}^{-1}$ (indicated by black dashed line). The ppp spectra also show the intensity has a small increment, and the peak width is broader at about $2840 \mathrm{~cm}^{-1}$, which is the resonant frequency $\nu_{\mathrm{s}}$ of the methyl group from $\mathrm{Ti}_{5 \mathrm{c}}-\mathrm{CH}_{3} \mathrm{OH}$ before UV irradiation. Another feature after UV irradiation is that the nonresonance increases with the irradiation time for both ssp and ppp spectra.

Figure 2 shows the SFG vibrational spectra before and after UV irradiation, which are similar as in Figure 1, except that the substrate was kept at $180 \mathrm{~K}$ when it was irradiated by UV light. The temperature of $180 \mathrm{~K}$ is just about $20 \mathrm{~K}$ below the temperature where the first-layer methanol starts desorbing. ${ }^{8}$ In Figure 2a, after only $10 \mathrm{~s}$ of UV light irradiation, the $\nu_{\mathrm{s}}$ feature of methoxy dramatically drops in the ssp spectra, while the intensity of the $\nu_{\mathrm{s}}$ feature of methanol turns broader. In Figure $2 b$, the ppp spectra show much difference after UV irradiation. The $\nu_{\mathrm{s}}$ feature of methoxy decreases with the UV irradiation time, while the peak at about $2840 \mathrm{~cm}^{-1}$, assigned to the $\nu_{\mathrm{s}}$ of methanol previously, turns broader, and the intensity increases obviously. However, adsorbed methanol should not increase after UV irradiation. There must be some resonance from some new product with similar frequency occasionally. In addition, after only $2 \mathrm{~s}$ of UV light irradiation, the ppp spectra show an obviously new feature at around 2770 $\mathrm{cm}^{-1}$. After further $10 \mathrm{~s}$ of UV irradiation, this feature continues increasing, the feature at about $2840 \mathrm{~cm}^{-1}$ also turns larger notably and another feature at about $3040 \mathrm{~cm}^{-1}$ arises.

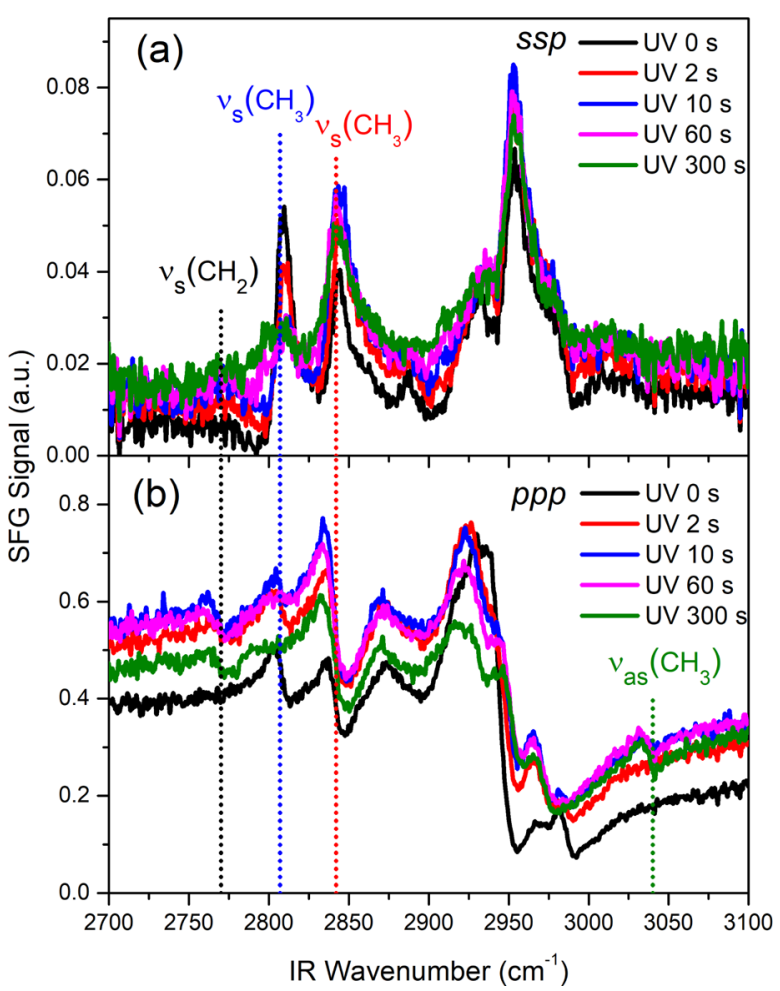

Figure 2. SFG vibrational spectra with ssp (a) and ppp (b) polarization combinations of methanol with one-layer coverage on the $\mathrm{TiO}_{2}(110)$ surface before and after variant UV irradiation times at $400 \mathrm{~nm}$. The substrate was kept at $180 \mathrm{~K}$ the substrate was irradiated by UV. The SFG spectra were taken by cooling down the substrate to $120 \mathrm{~K}$. Vertical dashed lines indicate the resonant frequencies of methoxy (blue), methanol (red), formaldehyde (black), and methyl formate (olive) on $\mathrm{Ti}_{5 c}$ sites.

Longer UV irradiation, both features at 2770 and $2840 \mathrm{~cm}^{-1}$ decrease and the feature at $3040 \mathrm{~cm}^{-1}$ becomes larger. The nonresonance in the ppp spectra shows an increase first and then decreases with the UV irradiation time, while that in the ssp spectra always increases. The increase of the nonresonance might be from the increasing excess electron density induced by surface hydroxyl groups from photocatalytic reactions. ${ }^{34}$ However, the different trends of polarization-dependent nonresonance is unclear, which is worth further investigation because of the importance of excess electrons on the surface reactions. $^{35}$

The methanol can be photo-oxidized to formaldehyde and methyl formate stepwise, which has been thoroughly studied. $^{23-26,36}$ Based on the spectral assignment of formaldehyde in the gas phase,,$^{37,38}$ in the condensed phase, ${ }^{39}$ and in the adsorbed layer on metals ${ }^{40}$ and oxides, ${ }^{41}$ we attribute 2770 and $2840 \mathrm{~cm}^{-1}$ to the symmetric $\left(\nu_{s}\left(\mathrm{CH}_{2}\right)\right)$ and antisymmetric $\left(\nu_{\text {as }}\left(\mathrm{CH}_{2}\right)\right)$ stretching modes, of $\mathrm{CH}_{2}$ from formaldehyde, respectively, where the frequency of $\nu_{\text {as }}\left(\mathrm{CH}_{2}\right)$ is coincident with that of $\nu_{\mathrm{s}}\left(\mathrm{CH}_{3}\right)$ of methanol on $\mathrm{Ti}_{5 \mathrm{c}}$. They are only a little redshift compared with the vibration frequency in the gas phase. This implies that the relating electronic structure of formaldehyde is only weakly perturbed, which is consistent with the theoretical simulation about the $2 \pi^{*}$ state. ${ }^{42}$ Based on the infrared spectroscopic studies of methyl formate in the gas phase $^{43}$ and on oxides, ${ }^{4-46}$ we assign the feature at $3040 \mathrm{~cm}^{-1}$ to the antisymmetric stretching mode of $\mathrm{CH}_{3}$ of methyl formate. This also agrees with the conclusion that the ppp 
intensity is always many times that for ssp. ${ }^{47}$ Concerning the methyl formate, there should be other two resonant peaks in the range of 2940 to $2970 \mathrm{~cm}^{-1}$, which are the symmetric stretching of $\mathrm{CH}$ and $\mathrm{CH}_{3}$. However, because of the complicated spectral overlapping, it is almost impossible to get the reasonable fitting of these spectra. Hence, we cannot get these resonant frequencies. Table 1 summarizes the spectral assignments of the methanol and the photocatalytic reaction products, formaldehyde and methyl formate, on $\mathrm{TiO}_{2}(110)$ in the $\mathrm{C}-\mathrm{H}$ stretching range.

Table 1. Assignments of Vibrational Frequencies $\left(\mathrm{cm}^{-1}\right)$ of Methanol and the Photocatalytic Reaction Products, Formaldehyde and Methyl Formate, on $\mathrm{TiO}_{2}(110)$ in the C-H Stretching Range

\begin{tabular}{|c|c|c|c|c|c|c|}
\hline \multicolumn{7}{|c|}{$\mathrm{CH}_{3} \mathrm{OH}$} \\
\hline \multicolumn{2}{|c|}{ assignment $^{33}$} & \multicolumn{2}{|c|}{$\mathrm{CH}_{3} \mathrm{O}-\mathrm{Ti}_{5 \mathrm{c}}$} & \multicolumn{3}{|c|}{$\mathrm{CH}_{3} \mathrm{OH}-\mathrm{Ti}_{5 \mathrm{c}}$} \\
\hline \multicolumn{2}{|c|}{$\nu_{\mathrm{s}}\left(\mathrm{CH}_{3}\right)$} & \multicolumn{2}{|c|}{2806} & \multicolumn{3}{|c|}{2841} \\
\hline \multicolumn{7}{|c|}{$\mathrm{CH}_{2} \mathrm{O}$} \\
\hline assignment & $\mathrm{TiO}_{2}(110)$ & $\operatorname{gas}^{37,38}$ & solid $^{39}$ & $\operatorname{Ag}(110)^{40}$ & $\mathrm{SiO}_{2}^{41}$ & $\mathrm{Al}_{2} \mathrm{O}_{3}^{41}$ \\
\hline$\nu_{\mathrm{s}}\left(\mathrm{CH}_{2}\right)$ & 2770 & 2782 & 2831 & 2850 & 2830 & 2818 \\
\hline$\nu_{\mathrm{as}}\left(\mathrm{CH}_{2}\right)$ & $\sim 2840$ & 2843 & 2886 & & 2894 & 2885 \\
\hline \multicolumn{7}{|c|}{$\mathrm{CH}_{3} \mathrm{COOH}$} \\
\hline assignment & $\mathrm{TiO}_{2}(11$ & & as $^{43}$ & powdered $\mathrm{T}$ & $\mathrm{O}_{2}{ }^{46}$ & $\mathrm{SiO}_{2}{ }^{44}$ \\
\hline$\nu_{s}(\mathrm{CH})$ & & & 943 & & & 2952 \\
\hline$\nu_{\mathrm{s}}\left(\mathrm{CH}_{3}\right)$ & & & 969 & 2960 & & 2964 \\
\hline$\nu_{\text {as }}\left(\mathrm{CH}_{3}\right)$ & 3040 & & 045 & 3040 & & 3044 \\
\hline
\end{tabular}

By comparing the depletion in the ssp spectra under UV irradiation between Figures $1 \mathrm{a}$ and $2 \mathrm{a}$, we can find that the photocatalytic reaction for the substrate at $180 \mathrm{~K}$ is much more efficient than that for the substrate at $120 \mathrm{~K}$. This temperature dependence of the photocatalytic reaction rate has also been observed before with the low-coverage methanol on $\mathrm{TiO}_{2}(110) .^{24,48}$ Further, only a little formaldehyde and no methyl formate was produced even after further longer UV irradiation when the substrate was at $120 \mathrm{~K}$. However, when the substrate was at $180 \mathrm{~K}$, we observed not only the production of more formaldehyde but also its depletion and the production of methyl formate. This is consistent with the former reports. ${ }^{24,25}$ The only difference between two measurements is the temperature of the substrate when UV shining. The temperature of $180 \mathrm{~K}$ is almost the onset of methanol diffusion along the surface $\mathrm{Ti}_{5 \mathrm{c}}$ row from the TPD and STM results. ${ }^{8,22}$

Each step of methanol photooxidation to methoxy, formaldehyde, and further to methyl formate produces the $\mathrm{H}$ atom on the $\mathrm{O}_{b}$ site to form $\mathrm{OH}_{\mathrm{b}}$. There is strong repulsion between these $\mathrm{OH}_{\mathrm{b}}$ species. ${ }^{49,50}$ This repulsion inhibits the new generation of the closed $\mathrm{OH}_{\mathrm{b}}$, which suggests dissociation, and further photo-oxidation of methanol is prevented. As a result, the reaction could be slower and could even stop when the $\mathrm{OH}_{\mathrm{b}}$ density is high. However, when the substrate was warmed up and allowed the diffusion of methanol, the newly generated $\mathrm{H}$ atom could move apart from the existing $\mathrm{OH}_{\mathrm{b}}$. The $\mathrm{OH}_{\mathrm{b}}$ can hop between the different rows of the bridgebonded $\mathrm{O}$ row assisted by the mobile methanol on $\mathrm{Ti}_{5 \mathrm{c}}$ sites, ${ }^{11}$ which can also increase the distance between $\mathrm{OH}_{\mathrm{b}}$ 's and reduce their repulsion. The much diffusive formaldehyde may separate from the $\mathrm{OH}_{\mathrm{b}}$, and close to the methoxy, which can also favor the production of methyl formate. ${ }^{48,51}$
3.2. Methanol Dissociation on Hydroxylated $\mathrm{TiO}_{2}(110)$ Studied by STM. To further determine the effect from the hydroxyl group on the photocatalytic reaction of methanol on $\mathrm{TiO}_{2}(110)$, we carried out the STM studies on methanol dissociation on the hydroxylated surface. Figure 3a$d$ shows a series of STM images of a single methanol molecule coadsorbed with neighboring $\mathrm{OH}_{\mathrm{b}}$ on the $\mathrm{TiO}_{2}(110)$ surface. The partially hydroxylated $\mathrm{TiO}_{2}(110)$ surface was prepared by dosing water on the surface to generate $\mathrm{OH}_{\mathrm{b}}$ and then flashing to $400 \mathrm{~K}$ to desorb molecular water. ${ }^{52}$ STM images are dominated by electronic effects rather than the geometric structure on the $\mathrm{TiO}_{2}(110)$ surface. ${ }^{53}$ In Figure $3 \mathrm{a}-\mathrm{d}$, the bright rows correspond to low-lying $\mathrm{Ti}_{5 \mathrm{c}}$ atoms, while the dark rows represent topographically high $\mathrm{O}_{\mathrm{b}}$ atoms. The faint bright protrusions on the $\mathrm{O}_{b}$ row are oxygen vacancies and the brighter spots on the $\mathrm{O}_{b}$ row are $\mathrm{OH}_{b}$ (marked by dashed circles in Figure 3 ). Figure $3 \mathrm{bl}$ shows the same area after dosing methanol molecules, and the bright round spot on the $\mathrm{Ti}_{5 \mathrm{c}}$ row can be clearly assigned as a methanol molecule next to $\mathrm{OH}_{\mathrm{b}}$.

After $45 \mathrm{~mW}$ laser irradiation for $10 \mathrm{~min}$, Figure $3 \mathrm{cl}$ shows dramatic changes. The bright round spot was changed into a big triangle feature, which looks like consisting of three parts, one big bright spot on the $\mathrm{Ti}_{5 \mathrm{c}}$ row with two faint bright spots on two neighboring $\mathrm{O}_{b}$ row. This feature is very similar to that of single methanol's photodissociation under $355 \mathrm{~nm}$ irradiation without $\mathrm{OH}_{\mathrm{b}}$ nearby, which is attributed to the formaldehyde molecule on the $\mathrm{Ti}_{5 \mathrm{c}}$ site one step away from the original methanol adsorption site and two $\mathrm{OH}_{\mathrm{b}}$, $\mathrm{s}^{42}$ With further laser irradiation of $85 \mathrm{~mW}$ for $10 \mathrm{~min}$ as shown in Figure $3 \mathrm{~d} 1$, the middle bright spot disappeared, while two spots on different $\mathrm{O}_{b}$ rows remained on the surface. It is noticed that the two spots have different sizes, and the big spot is brighter. After applying a $2 \mathrm{~V}$ pulse on the top of the big bright spot (marked by green arrow in Figure 3d1), it was changed into a small spot which resembles the $\mathrm{OH}_{\mathrm{b}}$ in Figure $3 \mathrm{al}$ (see Figure 3e1). Because the $\mathrm{H}$ atom of $\mathrm{OH}_{\mathrm{b}}$ can be easily removed by voltage above $2 \mathrm{~V},{ }^{42,54,55}$ the two bright features in Figure $3 \mathrm{cl}$ are attributed to an $\mathrm{OH}_{\mathrm{b}}$ pair ${ }^{56}$ on the left and a single $\mathrm{OH}_{\mathrm{b}}$ on the right. Hence, the triangle feature in Figure $3 \mathrm{cl}$ consists of a formaldehyde molecule in the middle and three $\mathrm{OH}_{\mathrm{b}}$ groups on both $\mathrm{O}_{\mathrm{b}}$ rows. In addition, the site where the formaldehyde sits is one $\mathrm{Ti}_{5 \mathrm{c}}$ atom away from the original $\mathrm{Ti}_{5 \mathrm{c}}$ site the methanol adsorbs. This phenomenon is quite different from that of a single methanol on $\mathrm{TiO}_{2}(110)$, that is, both $\mathrm{OH}_{\mathrm{b}}$ groups from the photodissociation of a single methanol sit on neighboring $\mathrm{O}_{\mathrm{b}}$ sites. ${ }^{42}$ Meanwhile, we also observed another condition, as indicated in Figure 3a2-e2. The difference is that the two $\mathrm{H}$ atoms from methanol dissociation are on the same $\mathrm{O}_{b}$ row. From the comparison between Figure 3a2,b2, the marked position of $\mathrm{OH}_{b}$ changes by one lattice distance, which could be attributed to the $\mathrm{OH}_{\mathrm{b}}$ diffusion mediated by the adsorbed methanol. ${ }^{11}$ Hence, it is also possible that $\mathrm{OH}_{b}$ diffuses to the opposite $\mathrm{O}_{b}$ row under UV light irradiation in Figure 3c2,d2.

The dissociation of methanol with neighboring $\mathrm{OH}_{\mathrm{b}}$ was observed by STM, while the dissociation possibility is largely different from that on the surface without neighboring $\mathrm{OH}_{\mathrm{b}}$. To further study the $\mathrm{OH}_{\mathrm{b}}$ effect on methanol dissociation, qualitative analysis was carried out. During our experiments, after multitime laser irradiation, only $20 \%(3 / 15)$ of the methanol molecules with neighboring $\mathrm{OH}_{\mathrm{b}}$ were dissociated, while the dissociation rate without neighboring $\mathrm{OH}_{\mathrm{b}}$ is about 

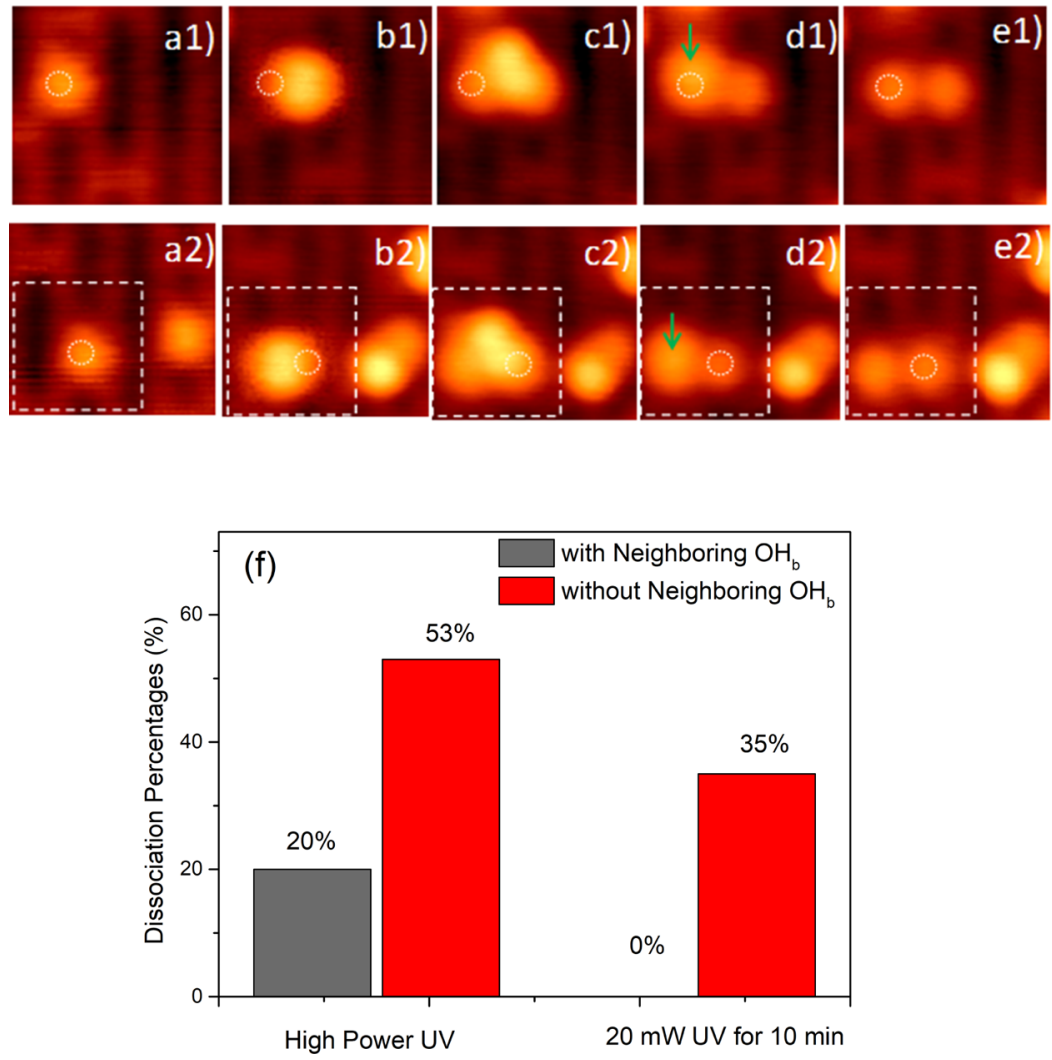

Figure 3. STM images of the photochemical process of methanol molecules with an $\mathrm{OH}_{\mathrm{b}}$ on the neighbored $\mathrm{BBO}$ site under multiple $355 \mathrm{~nm}$ irradiation periods $(2.3 \mathrm{~nm} \times 2.3 \mathrm{~nm}, 1.25 \mathrm{~V} 100 \mathrm{pA})$. (a1,a2) Patically hydroxylated $\mathrm{TiO}_{2}(110)$ surface. (b1,b2) Same surface with methanol adsorption which appears as a bright round spot. (c1,c2) In situ images after $45 \mathrm{~mW}$ laser irradiation for $15 \mathrm{~min}$. (d1,d2) After another $85 \mathrm{~mW}$ laser irradiation for $10 \mathrm{~min}$, an $\mathrm{OH}_{\mathrm{b}}$ pair and a single $\mathrm{OH}_{\mathrm{b}}$ remained on the surface. (e1,e2) Removal of one $\mathrm{H}$ of the $\mathrm{OH}_{\mathrm{b}}$ pair by adding $2 \mathrm{~V} 10 \mathrm{~ms}$ pulse on the surface. The dashed rectangles mark the reaction region, and the green arrows and dashed circles represent the positions of adding pulse and $\mathrm{OH}_{\mathrm{b}} \mathrm{s}$ next to the reactive methanols, respectively. (f) Statistical results of methanol dissociation percentages with and without neighboring $\mathrm{OH}_{\mathrm{b}}$ under high-power $\mathrm{UV}$ for multi-irradiation (see the main text) and $20 \mathrm{~mW}$ for $10 \mathrm{~min}$.

$53 \%(28 / 53)$ under the same irradiation condition (the same irradiation power and total duration). Moreover, with the lower UV excitation flux, the difference is larger. After the firsttime irradiation of about $20 \mathrm{~mW}$ for $10 \mathrm{~min}$, no methanol dissociation was observed with neighboring $\mathrm{OH}_{\mathrm{b}}$, while $35 \%$ $(19 / 53)$ of the methanol molecules without neighboring $\mathrm{OH}_{\mathrm{b}}$ were dissociated. It was found that the coexistence of the methoxy on $\mathrm{Ti}_{5 \mathrm{c}}$ and $\mathrm{OH}_{\mathrm{b}}$ significantly decreases the yield of formaldehyde because of the reverse reaction from methoxy on $\mathrm{Ti}_{5 \mathrm{c}}$ and $\mathrm{OH}_{\mathrm{b}}$ to $\mathrm{CH}_{3} \mathrm{OH} .^{48,57}$ The additional neighboring $\mathrm{OH}_{\mathrm{b}}$ must increase the reverse reaction possibility and lower the photodissociation of methanol.

From the principle of photocatalytic reactions on $\mathrm{TiO}_{2}$, which is generally accepted, ${ }^{1}$ the competition with charge transfer to adsorbed species is mainly the recombination of the electron and hole. Recombination can occur in bulk or on the surface with the release of heat or phonon excitation, which was considered as a detriment to the efficiency of the photocatalyst. However, the conclusion from our experiment results above shows that the thermal motion can enhance the photocatalytic reaction. Intensive UV light, like ultrashort pulsed light, might excite multiple electron and hole pairs in a short time. The massive electron and hole recombination could rapidly generate high excitation of local phonons, ${ }^{29}$ which in turn raises the motion and diffusion of adsorbates in tens picosecond scale. ${ }^{58}$ Thus, it can increase the photocatalytic reaction. Hence, the recombination of the electron and hole might not have a complete negative effect in photocatalytic reaction processes. From the comparison of results with the high-power and the lower-power UV irradiation in STM experiments above and the high-intensive UV light ${ }^{23}$ and lowintensive continuous wave light ${ }^{21}$ in the literature, the highintensive UV light could dramatically enhance the quantum yield of photocatalytic reactions. High-energy charge carriers can be generated by photons, which are larger than the band gap. These charge carriers in $\mathrm{TiO}_{2}$ rapidly thermalize to their respective band edges because of carrier-carrier and carrierphonon scatterings, and local phonons can be excited in the meantime. These excited phonons, or the local heat, can promote the movement and mobility of the adsorbate and then increase the photocatalytic reaction. This could be another possible mechanism to explain the strong photon energy dependence of the photocatalytic dissociation rate of methanol on $\mathrm{TiO}_{2}(110)$, which has been observed. ${ }^{29}$

\section{CONCLUSIONS}

In summary, we used surface SFG-VS in the $\mathrm{C}-\mathrm{H}$ stretching range to in situ identify the photocatalytic products, formaldehyde and methyl formate, of methanol on $\mathrm{TiO}_{2}(110)$. This provides the vibrational assignment information for future possible time-resolved experiments on the photocatalytic reaction dynamics. We also observed the temperature dependence of photocatalytic reaction and proposed that the diffusion of adsorbates limits the further photocatalytic 
reaction because of the repulsion from $\mathrm{OH}_{\mathrm{b}}$. Further evidence of the inhibition of photocatalytic reactions from $\mathrm{OH}_{b}$ was provided by STM experiments combined with UV light on the photodissociation of methanol on the hydroxylated $\mathrm{TiO}_{2}(110)$ surface. This work provides detailed insights into the photooxidation of methanol on $\mathrm{TiO}_{2}(110)$ and help better understand the photochemistry of organic molecules on oxides at the molecular level.

\section{AUTHOR INFORMATION}

\section{Corresponding Authors}

*E-mail: zhbma@dicp.ac.cn (Z.M.).

*E-mail: zfren@dicp.ac.cn (Z.R.).

\section{ORCID}

Haochen Wang: 0000-0003-0234-7932

Qing Guo: 0000-0003-0265-1184

Chuanyao Zhou: 0000-0002-3252-2992

Zefeng Ren: 0000-0002-5263-9346

\section{Author Contributions}

${ }^{\perp}$ R.Z. and H.W. contributed equally to this work.

\section{Notes}

The authors declare no competing financial interest.

\section{ACKNOWLEDGMENTS}

This work was supported by the Ministry of Science and Technology (grant nos. 2018YFA0208700 and 2016YFA0200602), Chinese Academy of Sciences (grant no. XDB17000000), National Natural Science Foundation of China (grant nos. 91645125, 21673236 and 21688102), and the Youth Innovation Promotion Association of CAS under grant no. 2017224.

\section{REFERENCES}

(1) Linsebigler, A. L.; Lu, G.; Yates, J. T. Photocatalysis on $\mathrm{TiO}_{2}$ Surfaces: Principles, Mechanisms, and Selected Results. Chem. Rev. $1995,95,735-758$.

(2) Thompson, T. L.; Yates, J. T. Surface science studies of the photoactivation of $\mathrm{TiO}_{2}$-new photochemical processes. Chem. Rev. 2006, 106, 4428-4453.

(3) Dohnálek, Z.; Lyubinetsky, I.; Rousseau, R. Thermally-driven Processes on Rutile $\mathrm{TiO}_{2}(110)-(1 \times 1)$ : A Direct View at the Atomic Scale. Prog. Surf. Sci. 2010, 85, 161-205.

(4) Chen, H.; Nanayakkara, C. E.; Grassian, V. H. Titanium Dioxide Photocatalysis in Atmospheric Chemistry. Chem. Rev. 2012, 112, $5919-5948$.

(5) Henderson, M. A.; Lyubinetsky, I. Molecular-Level Insights into Photocatalysis from Scanning Probe Microscopy Studies on $\mathrm{TiO}_{2}(110)$. Chem. Rev. 2013, 113, 4428-4455.

(6) Guo, Q.; Zhou, C.; Ma, Z.; Ren, Z.; Fan, H.; Yang, X. Elementary photocatalytic chemistry on $\mathrm{TiO}_{2}$ surfaces. Chem. Soc. Rev. 2016, 45, 3701-3730.

(7) Guo, Q.; Zhou, C.; Ma, Z.; Ren, Z.; Fan, H.; Yang, X. Elementary Chemical Reactions in Surface Photocatalysis. Annu. Rev. Phys. Chem. 2018, 69, 451-472.

(8) Henderson, M. A.; Otero-Tapia, S.; Castro, M. E. The Chemistry of Methanol on the $\mathrm{TiO}_{2}(110)$ Surface: the Influence of Vacancies and Coadsorbed Species. Faraday Discuss. 1999, 114, 313-329.

(9) Farfan-Arribas, E.; Madix, R. J. Role of Defects in the Adsorption of Aliphatic Alcohols on the $\mathrm{TiO}_{2}(110)$ Surface. J. Phys. Chem. B 2002, 106, 10680-10692.

(10) Farfan-Arribas, E.; Madix, R. J. Different binding sites for methanol dehydrogenation and deoxygenation on stoichiometric and defective $\mathrm{TiO}_{2}(110)$ surfaces. Surf. Sci. 2003, 544, 241-260.
(11) Zhang, Z.; Bondarchuk, O.; White, J. M.; Kay, B. D.; Dohnálek, Z. Imaging Adsorbate O-H Bond Cleavage: Methanol on $\mathrm{TiO}_{2}(110)$. J. Am. Chem. Soc. 2006, 128, 4198-4199.

(12) de Armas, R. S.; Oviedo, J.; San Miguel, M. A.; Sanz, J. F. Methanol adsorption and dissociation on $\mathrm{TiO}_{2}(110)$ from first principles calculations. J. Phys. Chem. C 2007, 111, 10023-10028.

(13) Zhao, J.; Yang, J.; Petek, H. Theoretical study of the molecular and electronic structure of methanol on a $\mathrm{TiO}_{2}(110)$ surface. Phys. Rev. B: Condens. Matter Mater. Phys. 2009, 80, 235416.

(14) Zhou, C.; Ren, Z.; Tan, S.; Ma, Z.; Mao, X.; Dai, D.; Fan, H.; Yang, X.; LaRue, J.; Cooper, R.; Wodtke, A. M.; Wang, Z.; Li, Z.; Wang, B.; Yang, J.; Hou, J. Site-specific Photocatalytic Splitting of Methanol on $\mathrm{TiO}_{2}(110)$. Chem. Sci. 2010, 1, 575-580.

(15) Sánchez, V. M.; Cojulun, J. A.; Scherlis, D. A. Dissociation Free Energy Profiles for Water and Methanol on $\mathrm{TiO}_{2}$ Surfaces. J. Phys. Chem. C 2010, 114, 11522-11526.

(16) Bates, S. P.; Gillan, M. J.; Kresse, G. Adsorption of Methanol on $\mathrm{TiO}_{2}(110)$ : A First-Principles Investigation. J. Phys. Chem. B 1998, 102, 2017-2026.

(17) Kawai, T.; Sakata, T. Photocatalytic hydrogen production from liquid methanol and water. J. Chem. Soc., Chem. Commun. 1980, 15, 694-695.

(18) Kawai, M.; Naito, S.; Tamaru, K.; Kawai, T. The mechanism of photocatalytic hydrogen production from gaseous methanol and water: IR spectroscopic approach. Chem. Phys. Lett. 1983, 98, 377380.

(19) Harada, H.; Ueda, T. Photocatalytic activity of ultra-fine rutile in methanol-water solution and dependence of activity on particle size. Chem. Phys. Lett. 1984, 106, 229-231.

(20) Al-Mazroai, L. S.; Bowker, M.; Davies, P.; Dickinson, A.; Greaves, J.; James, D.; Millard, L. The photocatalytic reforming of methanol. Catal. Today 2007, 122, 46-50.

(21) Shen, M.; Henderson, M. A. Identification of the Active Species in Photochemical Hole Scavenging Reactions of Methanol on $\mathrm{TiO}_{2}$. J. Phys. Chem. Lett. 2011, 2, 2707-2710.

(22) Shen, M.; Acharya, D. P.; Dohnálek, Z.; Henderson, M. A. Importance of Diffusion in Methanol Photochemistry on TiO2(110). J. Phys. Chem. C 2012, 116, 25465-25469.

(23) Guo, Q.; Xu, C.; Ren, Z.; Yang, W.; Ma, Z.; Dai, D.; Fan, H.; Minton, T. K.; Yang, X. Stepwise Photocatalytic Dissociation of Methanol and Water on $\mathrm{TiO}_{2}(110)$. J. Am. Chem. Soc. 2012, 134, 13366-13373.

(24) Guo, Q.; Xu, C.; Yang, W.; Ren, Z.; Ma, Z.; Dai, D.; Minton, T. K.; Yang, X. Methyl Formate Production on $\mathrm{TiO}_{2}(110)$, Initiated by Methanol Photocatalysis at $400 \mathrm{~nm}$. J. Phys. Chem. C 2013, 117, $5293-5300$.

(25) Yuan, Q.; Wu, Z.; Jin, Y.; Xu, L.; Xiong, F.; Ma, Y.; Huang, W. Photocatalytic Cross-Coupling of Methanol and Formaldehyde on a Rutile $\mathrm{TiO}_{2}$ (110) Surface. J. Am. Chem. Soc. 2013, 135, 5212-5219.

(26) Phillips, K. R.; Jensen, S. C.; Baron, M.; Li, S.-C.; Friend, C. M. Sequential Photo-oxidation of Methanol to Methyl Formate on $\mathrm{TiO}_{2}$ (110). J. Am. Chem. Soc. 2012, 135, 574-577.

(27) Xu, C.; Yang, W.; Guo, Q.; Dai, D.; Chen, M.; Yang, X. Molecular Hydrogen Formation from Photocatalysis of Methanol on $\mathrm{TiO}_{2}(110)$. J. Am. Chem. Soc. 2013, 135, 10206-10209.

(28) Liu, S.; Liu, A.-a.; Wen, B.; Zhang, R.; Zhou, C.; Liu, L.-M.; Ren, Z. Coverage Dependence of Methanol Dissociation on $\mathrm{TiO}_{2}(110)$. J. Phys. Chem. Lett. 2015, 6, 3327-3334.

(29) Xu, C.; Yang, W.; Ren, Z.; Dai, D.; Guo, Q.; Minton, T. K.; Yang, X. Strong Photon Energy Dependence of the Photocatalytic Dissociation Rate of Methanol on $\mathrm{TiO}_{2}(110)$. J. Am. Chem. Soc. 2013, 135, 19039-19045.

(30) Chabal, Y. J. Surface infrared spectroscopy. Surf. Sci. Rep. 1988, 8, 211-357.

(31) Wang, Y.; Wöll, C. Chemical reactions on metal oxide surfaces investigated by vibrational spectroscopy. Surf. Sci. 2009, 603, 15891599.

(32) Liu, S.; Liu, A.-a.; Zhang, R.; Ren, Z. Compact ultrahigh vacuum/high-pressure system for broadband infrared sum frequency 
generation vibrational spectroscopy studies. Rev. Sci. Instrum. 2016, $87,044101$.

(33) Liu, A.-a.; Liu, S.; Zhang, R.; Ren, Z. Spectral Identification of Methanol on $\mathrm{TiO}_{2}(110)$ Surfaces with Sum Frequency Generation in the C-H Stretching Region. J. Phys. Chem. C 2015, 119, 2348623494.

(34) Feng, R.-r.; Liu, A.-a.; Liu, S.; Shi, J.; Zhang, R.; Ren, Z. In Situ Studies on the Dissociation and Photocatalytic Reactions of $\mathrm{CH}_{3} \mathrm{OH}$ on $\mathrm{TiO}_{2}$ Thin Film by Sum Frequency Generation Vibrational Spectroscopy. J. Phys. Chem. C 2015, 119, 9798-9804.

(35) Pang, C. L.; Lindsay, R.; Thornton, G. Chemical reactions on rutile $\mathrm{TiO}_{2}(110)$. Chem. Soc. Rev. 2008, 37, 2328-2353.

(36) Wei, D.; Jin, X.; Huang, C.; Dai, D.; Ma, Z.; Li, W.-X.; Yang, X. Direct Imaging Single Methanol Molecule Photocatalysis on Titania. J. Phys. Chem. C 2015, 119, 17748-17754.

(37) Khoshkhoo, H.; Nixon, E. R. Infrared and Raman spectra of formaldehyde in argon and nitrogen matrices. Spectrochim. Acta, Part A 1973, 29, 603-612.

(38) Brown, L. R.; Hunt, R. H.; Pine, A. S. Wavenumbers, line strengths, and assignments in the Doppler-limited spectrum of formaldehyde from 2700 to $3000 \mathrm{~cm}^{-1}$. J. Mol. Spectrosc. 1979, 75, 406-428.

(39) Khoshkoo, H.; Hemple, S. J.; Nixon, E. R. Infrared and Raman studies of solid formaldehyde. Spectrochim. Acta, Part A 1974, 30, $863-868$.

(40) Stuve, E. M.; Madix, R. J.; Sexton, B. A. An EELS study of the oxidation of $\mathrm{H}_{2} \mathrm{CO}$ on $\mathrm{Ag}(110)$. Surf. Sci. 1982, 119, 279-290.

(41) Busca, G.; Lamotte, J.; Lavalley, J. C.; Lorenzelli, V. FT-IR study of the adsorption and transformation of formaldehyde on oxide surfaces. J. Am. Chem. Soc. 1987, 109, 5197-5202.

(42) Wei, D.; Jin, X.; Huang, C.; Dai, D.; Ma, Z.; Li, W.-X.; Yang, X. Direct Imaging Single Methanol Molecule Photocatalysis on Titania. J. Phys. Chem. C 2015, 119, 17748-17754.

(43) Shimanouchi, T. Tables of Molecular Vibrational Frequencies Consolidated; National Bureau of Standards, 1972; Vol. I.

(44) Millar, G. J.; Rochester, C. H.; Waugh, K. C. Infrared study of methyl formate and formaldehyde adsorption on reduced and oxidised silica-supported copper catalysts. J. Chem. Soc., Faraday Trans. 1991, 87, 2785-2793.

(45) Millar, G. J.; Rochester, C. H.; Waugh, K. C. Evidence for the Adsorption of Molecules at Special Sites Located at Copper-Zinc Oxide Interfaces. J. Chem. Soc., Faraday Trans. 1992, 88, 3497-3503.

(46) Chuang, C.-C.; Wu, W.-C.; Huang, M.-C.; Huang, I.-C.; Lin, J.L. FTIR study of adsorption and reactions of methyl formate on powdered $\mathrm{TiO}_{2}$. J. Catal. 1999, 185, 423-434.

(47) Wang, H.-F.; Gan, W.; Lu, R.; Rao, Y.; Wu, B.-H. Quantitative spectral and orientational analysis in surface sum frequency generation vibrational spectroscopy (SFG-VS). Int. Rev. Phys. Chem. 2005, 24, 191-256.

(48) Feng, H.; Tan, S.; Tang, H.; Zheng, Q.; Shi, Y.; Cui, X.; Shao, X.; Zhao, A.; Zhao, J.; Wang, B. Temperature- and CoverageDependent Kinetics of Photocatalytic Reaction of Methanol on $\mathrm{TiO}_{2}(110)-(1 \mathrm{x}$ 1) Surface. J. Phys. Chem. C 2016, 120, 5503-5514.

(49) Li, S.-C.; Zhang, Z.; Sheppard, D.; Kay, B. D.; White, J. M.; Du, Y.; Lyubinetsky, I.; Henkelman, G.; Dohnálek, Z. Intrinsic Diffusion of Hydrogen on Rutile $\mathrm{TiO}_{2}(110)$. J. Am. Chem. Soc. 2008, 130, 9080-9088.

(50) Du, Y.; Petrik, N. G.; Deskins, N. A.; Wang, Z.; Henderson, M. A.; Kimmel, G. A.; Lyubinetsky, I. Hydrogen reactivity on highlyhydroxylated $\mathrm{TiO}_{2}(110)$ surfaces prepared via carboxylic acid adsorption and photolysis. Phys. Chem. Chem. Phys. 2012, 14, 3066-3074.

(51) Lang, X.; Wen, B.; Zhou, C.; Ren, Z.; Liu, L.-M. First-Principles Study of Methanol Oxidation into Methyl Formate on Rutile $\mathrm{TiO}_{2}(110)$. J. Phys. Chem. C 2014, 118, 19859-19868.

(52) Wendt, S.; Schaub, R.; Matthiesen, J.; Vestergaard, E. K.; Wahlström, E.; Rasmussen, M. D.; Thostrup, P.; Molina, L. M.; Lægsgaard, E.; Stensgaard, I.; Hammer, B.; Besenbacher, F. Oxygen vacancies on $\mathrm{TiO}_{2}(110)$ and their interaction with $\mathrm{H}_{2} \mathrm{O}$ and $\mathrm{O}_{2}$ : A combined high-resolution STM and DFT study. Surf. Sci. 2005, 598, 226-245.

(53) Diebold, U.; Anderson, J. F.; Ng, K.-O.; Vanderbilt, D. Evidence for the Tunneling Site on Transition-Metal Oxides: $\mathrm{TiO}_{2}(110)$. Phys. Rev. Lett. 1996, 77, 1322-1325.

(54) Zhang, Z.; Bondarchuk, O.; Kay, B. D.; White, J. M.; Dohnálek, Z. Imaging water dissociation on $\mathrm{TiO}_{2}(110)$ : Evidence for inequivalent geminate $\mathrm{OH}$ groups. J. Phys. Chem. B 2006, 110, 21840-21845.

(55) Bikondoa, O.; Pang, C. L.; Ithnin, R.; Muryn, C. A.; Onishi, H.; Thornton, G. Direct visualization of defect-mediated dissociation of water on $\mathrm{TiO}_{2}(110)$. Nat. Mater. 2006, 5, 189-192.

(56) Cui, X.; Wang, Z.; Tan, S.; Wang, B.; Yang, J.; Hou, J. G. Identifying Hydroxyls on the $\mathrm{TiO}_{2}(110)-1$ x 1 Surface with Scanning Tunneling Microscopy. J. Phys. Chem. C 2009, 113, 13204-13208.

(57) Mao, X.; Wei, D.; Wang, Z.; Jin, X.; Hao, Q.; Ren, Z.; Dai, D.; Ma, Z.; Zhou, C.; Yang, X. Recombination of Formaldehyde and Hydrogen Atoms on $\mathrm{TiO}_{2}(110)$. J. Phys. Chem. C 2015, 119, 11701174.

(58) Frischkorn, C.; Wolf, M. Femtochemistry at metal surfaces: Nonadiabatic reaction dynamics. Chem. Rev. 2006, 106, 4207-4233. 